\title{
A Praxeological Approach to Intentional Action ${ }^{1}$
}

Alan G. Futerman

Rosario, Argentina

e-mail: alanfuterman@catalactica.com.ar

Walter E. Block

Loyola University New Orleans, United States

e-mail: $\underline{\text { wblock@loyno.edu }}$

\begin{abstract}
:
The concept of Intentional Action is at the core of Praxeology, as developed by the Austrian economist Ludwig von Mises. Under this unique approach, defined as the science of human action and designed to study the field of the social sciences, Mises created an axiomatic-deductive system starting from the "action axiom": the contention that every acting man is eager to substitute a more satisfactory state of affairs for a less desired one. From this axiom, the Austrian scholar is able to derive the fundamental features and implications of human action; such as value, scale of value, scarcity, abundance, profit, loss, uncertainty and causality, among others. This paper intends to present the praxeological perspective on intentional action and its epistemological implications; it also attempts to answer objections to this thesis.
\end{abstract}

Keywords: Mises, action, praxeology, logic, Austrian economics.

\section{Introduction}

Praxeology, ${ }^{2}$ defined as the "Science of Human Action" and thoroughly developed by the Austrian School economist Ludwig von Mises ${ }^{3}$ in his magnum opus "Human Action" [65], is based on a specific approach towards the fundamental nature of intentional action. Mises, best known for his contributions to the debate on Economic Calculation under the Socialist system [62], is widely regarded today, along with Friedrich A. von Hayek, as the most important representative of the Austrian School of Economics in the $20^{\text {th }}$ century. ${ }^{4}$ The foundation of his entire defense of the free market system, ${ }^{5}$ in the tradition of classical liberalism, is based on the concept of action defined as purposeful behavior, i.e. intentional action. 
This approach is almost unique, since among the students of human behavior, Mises is one of the rare ones whose work consists in the development of an axiomatic-deductive system, which could pretend to explain the fundamental nature of human action as the basis for understanding the field of economics. ${ }^{6}$ Thus, "Economics, as a branch of the more general theory of human action, deals with all human action, i.e., with man's purposive aiming at the attainment of ends chosen, whatever these ends may be" [65, p. 880]. As we shall argue throughout this paper, praxeology is able to explain the basic nature of human action, and to do so under a unique epistemological foundation.

In order to make a case for praxeology's usefulness in understanding the nature of intentional action, first we will present its methodology and theory as an axiomatic-deductive system. Then we will analyze its postulates and their epistemological status, which will allow us to respond to possible objections and finally to present our conclusions.

\section{The Methodology of Praxeology}

We shall begin explaining Mises's specific ideas with respect to human action by showing his views on methodology. This is essential to the entire approach and the reason will be clear by the end of this section.

Mises can be defined as a methodological dualist, since he regards the method of the natural sciences as necessarily different from that of the social sciences, due to the idea that the former study regularities in nature, while the latter study concrete cases where human action is involved. ${ }^{7}$ This kind of phenomena, under a social context, constitutes complex phenomena, and therefore requires a different methodology for its analysis.

Methodological dualism is based on the fact that Mises identifies an ontological dualism between physical concretes and human actions, where the latter cannot be reduced to the former [98, $\mathrm{p}$. 2]. Thus, this implies that both phenomena must be treated differently while at the same time preserving a scientific approach to their study.

In the words of Mises:

The natural sciences too deal with past events. [...] But the experience to which the natural sciences owe all their success is the experience of the experiment in which the individual elements of change can be observed in isolation. [...] The experience with which the sciences of human action have to deal is always an experience of complex phenomena. No laboratory experiments can be performed with regard to human action. We are never in a position to observe the change in one element only, all other conditions of the event remaining unchanged. [...] The information conveyed by historical experience cannot be used as building material for the construction of theories and the prediction of future events. Every historical experience is open to various interpretations, and is in fact interpreted in different ways. The postulates of positivism and kindred schools of metaphysics are therefore illusory. It is impossible to reform the sciences of human action according to the pattern of physics and the other natural sciences. There is no means to establish an a posteriori theory of human conduct and social events. History can neither prove nor disprove any general statement in the manner in which the natural sciences accept or reject a hypothesis on the ground of laboratory experiments. Neither experimental verification nor experimental falsification of a general proposition is possible in its field (emphasis ours) [65, pp. $30-31]$.

As Mises explains, there is no such thing as ceteris paribus in the field of human action, ${ }^{8}$ although we may use such a concept in order to illustrate a specific idea (or conceive it). ${ }^{9}$ Thus, since no necessary regularities could be identified in this field, ${ }^{10}$ any use in the social sciences of concepts or methodological tools originated in the natural sciences would be an illegitimate extrapolation. ${ }^{11}$ 
Therefore, he naturally rejected the positivist approach as presented by the Vienna Circle (in the same way he fought the German Historical School).

The absence of regularities in human action, in turn, brings us a problem since we cannot proceed by generalizing from specific instances. Rather, we must utilize the hypothetic-deductive model of causal realism. Therefore, we cannot count on past events in order to create any specific model of human behavior, which we could use to predict future behavior, since "statistics is a method for the presentation of historical facts concerning prices and other relevant data of human action. It is not economics and cannot produce economic theorems and theories. The statistics of prices is economic history" [65, p. 348]. In effect, without theory we are not even able to understand past behavior. ${ }^{12}$ Thus, "there is no such thing as quantitative economics" [65, p. 348].

The historian can never derive theorems about cause and effect from the analysis of the material available. [...] This shows why it is wrong to contend that 'it is from observation that even deductive economics obtains its ultimate premises.' What we can 'observe' is always only complex phenomena. What economic history, observation, or experience can tell us is facts like these: Over a definite period of the past the miner John in the coal mines of the $X$ company in the village of $Y$ earned $p$ dollars for a working day of $n$ hours. There is no way that would lead from the assemblage of such and similar data to any theory concerning the factors determining the height of wage rates (emphasis ours) [67, p. 74].

What then, is the alternative to empirical scientific models in order to study human action? In Mises's view, to understand this field we need an axiomatic-deductive model. The central axiom of such a model should be a self-evident truth $^{13}$ (thus expressing its axiomatic nature ${ }^{14}$ ) by which theorems ought to be derived. These are later applied to the field of economics (catallactics ${ }^{15}$ ) in order to understand social phenomena. Such an axiom is defined as the "action axiom". "Thus, praxeology is based on the foundation of such an axiom. The fact that we could not know the ultimate end of every action ${ }^{17}$ does not imply that we could not engage in studying its structure.

The basis for the axiom as being self-evident is that we cannot deny it without engaging in a contradiction. This, in turn, provides the reason for its foundation as an irrefutable truth. In effect, its axiomatic nature implies that there is neither a possible nor a thinkable world where the axiom does not apply. ${ }^{18}$ Thus, it is non-falsifiable. ${ }^{19}$

Since we have explained the specific methodological approach taken by Mises, let us now examine what is the nature and scope of praxeology, based on the action axiom.

\section{The Logic of Intentional Action}

\section{Mises defines human action as}

[...] purposeful behavior. Or we may say: Action is will put into operation and transformed into an agency, is aiming at ends and goals, is the ego's meaningful response to stimuli and to the conditions of its environment, is a person's conscious adjustment to the state of the universe that determines his life. Such paraphrases may clarify the definition given and prevent possible misinterpretations. But the definition itself is adequate and does not need complement or commentary [65, p. 11].

As such, the action axiom consists in the fact that every "Acting man is eager to substitute a more satisfactory state of affairs for a less satisfactory" [65, p. 13]. Thus, the acting agent chooses those means that he subjectively identifies as the best in order to achieve his ends. 
Although Mises rejects mathematical economics, ${ }^{20}$ it can be useful to illustrate the action axiom and its theorems with the help of mathematical functions. ${ }^{21}$ In effect, if we say that every action (A) is a function of specific ends (E), then:

1) $A=f(E)$

This is so because if the acting agent has no ends he wishes to attain, then he will not engage in any action whatsoever. It must be also said that, in this respect, action always aims at a change in existing conditions, whether with respect to the acting man itself (autistic exchange), or to other/s (interpersonal exchange) [65, pp. 195 - 196]. In this regard, the focus of any specific action is irrelevant with respect to its fundamental character: it always purports to remove or alleviate some uneasiness.

In effect, human action is based on the presupposition that the subjective value that the individual gives to the end $(\mathrm{vE})$ he wishes to attain is higher than the subjective value he gives to his effort or means (vM) to achieve it.

2.a) If $v E>v M \rightarrow \exists A$

2.b) If $\mathrm{vE} \leq \mathrm{vM} \rightarrow \nexists \mathrm{A}$

Mises explains:

The most general prerequisite of action is a state of dissatisfaction, on the one hand, and, on the other, the possibility of removing or alleviating it by taking action. (Perfect satisfaction and its concomitant, the absence of any stimulus to change and action, belong properly to the concept of a perfect being. This, however, is beyond the power of the human mind to conceive. A perfect being would not act) (emphasis ours) [63, p. 25].

At any specific point in time, man wishes to attain several different ends, and therefore he will try to achieve those which he identifies as priorities according to his scale of preferences. How do we know it? Because if we follow 1) and 2.a), then it is obvious that the individual will act in order to achieve the end that he regards as most important, leaving the rest for a later time (according to his means). This is so because human action takes place in time (T), and depends on means (M); and since man cannot attain all the ends (E) he wishes simultaneously, ${ }^{22}$ he must necessarily choose. Such choice will be made according to some standard, thus ordering the ends with respect to the individual's judgment and values:

3.a) $\mathrm{E}_{1}, \mathrm{E}_{2}, \mathrm{E}_{3}, \ldots, \mathrm{E}_{n}$

3.b) $\mathrm{vE}_{1}>\mathrm{vE}_{2}>\mathrm{vE}_{3}>\ldots>\mathrm{vEn}$

3.c) $\mathrm{vE}_{n}=\mathrm{f}\left(\mathrm{E}_{n}\right)$

As we can see in 3.c) the value that the individual gives to any specific end will depend on the position of such end in his scale of preferences. Now we may turn our attention to means themselves. As every human action makes use of some means for the attainment of its ends, these means (M) are also valued by the acting agent. We call this valuation utility $(\mathrm{U})$, and it will be proportionate to the value that the individual gives to the end that could be attained with such unit of means. ${ }^{23}$

4.a) $\mathrm{M}_{1}, \mathrm{M}_{2}, \mathrm{M}_{3}, \ldots, \mathrm{M}_{n}$

4.b) $\mathrm{U}_{1}, \mathrm{U}_{2}, \mathrm{U}_{3}, \ldots, \mathrm{U}_{n}$ 
4.c) $\mathrm{M}=\mathrm{F}(\mathrm{E})$

4.d) $\mathrm{M}_{n}=\mathrm{F}\left(\mathrm{E}_{n}\right)$

4.e) $\mathrm{U}_{n}=\mathrm{F}\left(\mathrm{vE}_{n}\right)$

Since the individual chooses the means he subjectively regards as the best in order to achieve its ends (4.c, 4.d), according to his value scale (4.a, 4.b), we can see that the utility of every (unit of) means is determined by the value that the individual gives to the end that could be achieved with it (4.e). Thus, the utility of every unit of means is ultimately a function of the specific end that could be achieved with it and its value for the acting man:

4.f.) $\mathrm{M}_{n}=\mathrm{F}\left(\mathrm{E}_{n}\right) \rightarrow \mathrm{U}_{n}=\mathrm{F}\left(\mathrm{vE}_{n}\right)$

This in turn implies that, in many cases certain units of means may be used for different ends, while at the same time being interchangeable and relevant, i.e. any of them could be used for the attainment of any end, regardless of their ranking in the individual's scale of preferences. Therefore, the utility of every unit will be determined by the value of the last possible end (or lower ranked) that could be achieved with them (since this last end is the first one the individual would be willing to sacrifice if he had one less unit of means). Since the last end is called the marginal end (because it is on the margin ${ }^{24}$ ), and the last unit of means is called the marginal unit, the utility of this last unit is called marginal utility:

5.a) $\mathrm{M}_{1}=\mathrm{M}_{2}=\ldots=\mathrm{M}_{n} \rightarrow \mathrm{U}_{n}=\mathrm{f}\left(\mathrm{vE}_{n}\right)$

This is the foundation for the law of marginal utility. Since every end is arranged under a scale of preferences (3.a) and the value of each end depends on how it is ranked in such a scale (3.b), then utility will necessarily decrease as the individual acts in the attainment of more ends (4.f). Such is the fundamental reason behind diminishing marginal utility. ${ }^{25}$ Thus, as the individual increases its supply of units of means, $U$ will consequently decrease:

5.b) $\frac{\partial \mathrm{U}}{\partial \mathrm{Mn}}<0^{26}$

5.c) $\mathrm{U}_{1}\left(\mathrm{M}_{1}\right)>\mathrm{U}_{2}\left(\mathrm{M}_{2}\right)>\mathrm{U}_{3}\left(\mathrm{M}_{3}\right)>\ldots>\mathrm{U}_{n}\left(\mathrm{M}_{n}\right)$

Given the fact that each individual always has a specific amount of units of means to achieve its ends, if the amount of the former $(\mathrm{M} q)$ is lower than that of the latter $(\mathrm{E} q)$, therefore the individual will face scarcity. Thus, scarcity is a subjective evaluation of means with respect to ends, and not a particular feature of any given good (means).

6.a) $0<\mathrm{M} q<\infty$

6.b) $\mathrm{E} q>\mathrm{M} q$

Given (6.a) and (6.b), the acting agent faces scarcity. If he would have enough units of means in order to achieve every end (and even more), then the marginal utility of each unit would fall to zero, and thus he would not engage in any purposeful behavior (to achieve more ends), i.e. he would not act. ${ }^{27}$ This is because (2.b) would apply, where the effort to attain a specific end is valued more than the end itself.

Until this point we have only analyzed action ex ante. Let us now turn our attention to the implications of action ex post. The individual faces multiple possible different ends he could achieve with the means at his disposal. So, he will tend to choose which goals to attain according to his value 
scale $^{28}$ at any specific point in time (3.a, 3.b). Thus, the concept of cost $(C)$ is implicit in every human action. ${ }^{29}$ The value of the best-discarded alternative use of the unit of means would be the cost of each action (or, as economic theory presents it, the "opportunity cost").

7.a) $\mathrm{vE}_{1}>\mathrm{vE}_{2} \rightarrow \mathrm{A}=\mathrm{f}(\mathrm{E} 1)$ and $\mathrm{C}=\mathrm{vE}_{2}$

7.b) $\mathrm{vE}_{1}{ }^{\prime}>\mathrm{vE}_{2} \rightarrow \mathrm{P}$

7.c) $\mathrm{vE}_{1}^{\prime}<\mathrm{vE}_{2} \rightarrow \mathrm{L}$

As analyzed ex post, if the value the individual obtained by the action $\left(\mathrm{vE}_{1}\right.$ ') is greater than that given to the best other available option $\left(\mathrm{vE}_{2}\right)$, then he has in fact profited $(\mathrm{P})$ from such action. In case the opposite happens, he has experienced a loss (L).

We can infer from this that there is no such thing as indifference in the field of human action, (2.a, 2.b), since a truly indifferent agent does not act; cannot act. ${ }^{30}$ However, it may very well be the case that after the individual acts he may say he was indifferent with respect to acting in order to achieve $\mathrm{E}_{1}$ or $\mathrm{E}_{2}$. However, since this analysis is ex post, we do not have any other alternative but to assume that there was, ex ante, something in $\mathrm{E}_{1}$ that he found more valuable than $\mathrm{E}_{2} \cdot{ }^{31}$ Preference always reveals in action, and, despite the psychological implications that the concept of "indifference" may have, it has no economic consequences whatsoever.

In the case of interpersonal exchange, the price (p) is the amount of money paid for an item, or the other good, in the case of barter. If there is no voluntary exchange, always based on (2.a), then there is no price (which can be expressed in monetary terms or as a simple ratio of exchange between two commodities).

Another implication of the action axiom is time (T), since every action takes place in time and requires time in order to manifest itself and give place to an outcome. This in turn implies that the very same fact that the individual acts due to (2.a), means that it must be the case that he valued more the attainment of the end chosen in $t$ than in $t+1$ (8.a.).

Now consider:

8.a.) $\mathrm{vE}_{1} t>\mathrm{vE}_{1} t+1$

8.b.) $\mathrm{vE}_{1} t<\mathrm{vE}_{1} t+1 \rightarrow \nexists \mathrm{A}$

In effect, time preference (the ratio between the subjective value of the present with respect to the subjective value of the future) is an essential implication of human action.

8.c.) $\mathrm{TP}=\frac{\mathrm{vE} 1 t}{\mathrm{vE} 1 t+1}$

Thus, in order to sacrifice the achievement of the end at present for its accomplishment in the future, the individual will demand to receive in the future a higher value than that which he could have attained at present. In terms of present and future consumption, time preference (TP) explains the existence of interest and savings. The latter exists because it permits one to expand future consumption, which compensates for the sacrifice of postponing present consumption. ${ }^{32}$ Therefore, the individual will demand future consumption according to his time preference in order to sacrifice present consumption, i.e. the value of present consumption for the individual is defined by the present value of future consumption discounted by his rate of time preference.

An objection to the foregoing involved the famous ice-in-winter versus ice-in-summer example. ${ }^{33}$ It is now winter. A man, surely, will prefer the latter to the former. This seems like a refutation of the Austrian view that people always desire a good sooner rather than later. The refutation 
of this objection as that these two are not the same good, economically, even though they are, but only chemically.

Another implication of the action axiom is the concept of causality. This is so because unless the acting agent assumes that by doing $p$ (a specific action using specific means), he will not achieve $q$, then he would not engage in any action. In the view of Mises:

Man is in a position to act because he has the ability to discover causal relations which determine change and becoming in the universe. Acting requires and presupposes the category of causality. Only a man who sees the world in the light of causality is fitted to act. In this sense, we may say that causality is a category of action. The category means and ends presupposes the category cause and effect. In a world without causality and regularity of phenomena there would be no field for human reasoning and human action. Such a world would be a chaos in which man would be at a loss to find any orientation and guidance. Man is not even capable of imagining the conditions of such a chaotic universe. Where man does not see any causal relation, he cannot act. This statement is not reversible. Even when he knows the causal relation involved, man cannot act if he is not in a position to influence the cause (emphasis ours) [65, p. 22].

Thus, man will act only if he wishes to attain $q$, believes he had identified a causal relation of the type $p \rightarrow q$, and is able to engage in $p$. This, of course does not imply that causality should have a metaphysical character [98, p. 3], but that it has to be considered by the acting agent as such, if he wants to engage in any action. ${ }^{34}$

Should be clear by now what is the nature and corollaries (for praxeology) of intentional action, i.e. human action: ${ }^{35}$

As thinking and acting men, we grasp the concept of action. In grasping this concept we simultaneously grasp the closely correlated concepts of value, wealth, exchange, price, and cost. They are all necessarily implied in the concept of action, and together with them the concepts of valuing, scale of value and importance, scarcity and abundance, advantage and disadvantage, success, profit, and loss [...] There can be no doubt whatever concerning the aprioristic character of these disciplines (emphasis ours) [63, pp. $24-25]$.

\section{The Epistemological Implications of Praxeology}

Let us now analyze the epistemological implications of this unique approach toward intentional action. It must be clear by now that Mises ascribes to human action the condition of rationality. This requires further explanation, since this definition may at first sight appear as trying to justify every action as the proper one according to its specific context. But this is not the case, since Mises defines action as rational since it is always based in the selection of certain means for the attainment of specific ends, according to the subjective judgment of the individual who chooses to act. This in turn implies that, although the individual may be wrong, it does not follow that he did not regard the means chosen, at the time of choosing, as the best available to him. Mises defines as rational only the structure of human action, based on a means and ends approach, but not as an evaluative judgment. In other words, he does not regard rational action as necessarily the best choice that the individual could have made in a specific context (as judged by the best mind with the best knowledge in that context). But the fact that since he chose in a certain way, then it must necessarily follow that his judgment was made on the basis of his knowledge and based on his subjective considerations (value scale and preferences) as the standard. ${ }^{36}$ 
This also explains another feature of human action: uncertainty with respect to the future. Since man can experience both profit and loss, while he would always prefer to experience the former rather than the latter, it follows that he does not have perfect knowledge. ${ }^{37}$ Otherwise, men would always profit from every action they undertake, thus implying that there would neither be a concept of loss nor of profit (since this would be the standard). Man cannot always be right, and automatically so.

We may also ask why the category of action, as presented in praxeology, is an axiom. Its axiomatic nature comes from the fact that there is no possible way of escaping its truth. Even in the act of trying to deny the validity of the action axiom, one would have to choose certain means (arguments) in order to attain an end (refute the action axiom). In addition, one would have to assume that the act of trying to refute the axiom makes one pass from a less satisfactory state to a more satisfactory one. Thus any individual who tries to refute the action axiom affirms it in the very act of trying to deny it. ${ }^{38}$

Mises was deeply influenced by Kant [63], [67]. By talking about the category of action as inherent in the structure of the human mind, Mises regards it as a Kantian category. ${ }^{39}$ In effect, the action axiom is presented as a synthetic a priori proposition. Its truth is independent from any experience (thus making it a priori), while it is also present in every human action in the real empirical world (thus making it synthetic).

This does not imply that the concept of action cannot be learned. The a priori refers here to the identification of an essential attribute in human nature, and therefore an intrinsic characteristic of man; not necessarily the concept of a priori as prior to experience (as developed by John Stuart Mill). What Mises tells us is that the axiom is independent of experience, not that no experience is required in order to gain conscious awareness of its existence. In effect, by identifying the action axiom one is in fact engaging in an action. ${ }^{40}$ In other words, the identification of the concept of action is a posteriori (in the sense of Mill), but the category of action itself is a priori since it responds to a fundamental attribute of human nature, independent of whether such an attribute has been conceptualized or not. ${ }^{41}$ Thus, the action axiom is not to be understood as a tautology of the same kind as those in logic and mathematics, applicable to any universe possible or thinkable; rather, it is especially applicable to the concrete universe of experience of human beings and at the same time necessary.

The a priori knowledge of praxeology is entirely different - categorially different - from the a priori knowledge of mathematics or, more precisely, from mathematical a priori knowledge as interpreted by logical positivism. The starting point of all praxeological thinking is not arbitrarily chosen axioms, but a self-evident proposition, fully, clearly and necessarily present in every human mind. [...] The characteristic feature of man is precisely that he consciously acts. [...] To act means: to strive after ends, that is, to choose a goal and to resort to means in order to attain the goal sought.

The essence of logical positivism is to deny the cognitive value of a priori knowledge by pointing out that all a priori propositions are merely analytic. They do not provide new information, but are merely verbal or tautological, asserting what has already been implied in the definitions and premises. Only experience can lead to synthetic propositions. There is an obvious objection against this doctrine, viz., that this proposition that there are no synthetic a priori propositions is in itself $a-$ as the present writer thinks, false - synthetic a priori proposition, for it can manifestly not be established by experience(emphasis ours) [67, pp. 4 5]. 


\section{Objections to the Praxeological Approach and Possible Answers}

\subsection{Psychologism and Polylogism}

Although the argument by Mises seems compelling, possible objections may arise. Despite of the fact that human action is rational action; how can we know, in any specific case whether the individual's behavior corresponds to an action or a "reflex"? Mises himself recognizes that "Human action is conscious behavior on the part of a human being. Conceptually it can be sharply and clearly distinguished from unconscious activity, even though in some cases it is perhaps not easy to determine whether given behavior is to be assigned to one or the other category" (emphasis ours) [63, p. 24]. If we do not have any criteria in order to identify human action as such, then praxeology, although true $a$ priori, would be useless in practice (and the action axiom would no longer be a synthetic a priori proposition).

Mises replies that

[...] all experience concerning human action is conditioned by the praxeological categories and becomes possible only through their application. If we had not in our mind the schemes provided by praxeological reasoning, we should never be in a position to discern and to grasp any action. We would perceive motions, but neither buying nor selling, nor prices, wage rates, interest rates, and so on. It is only through the utilization of the praxeological scheme that we become able to have an experience concerning an act of buying and selling, but then independently of the fact of whether or not our senses concomitantly perceive any motions of men and of nonhuman elements of the external world. Unaided by praxeological knowledge we would never learn anything about media of exchange. If we approach coins without such preexisting knowledge, we would see in them only round plates of metal, nothing more. Experience concerning money requires familiarity with the praxeological category medium of exchange (emphasis ours) $[65, \mathrm{p} .40] .{ }^{42}$

Although we could say that this answer to the problem makes sense, it is only a partial solution. ${ }^{43} \mathrm{We}$ need a stronger foundation for praxeology, and as we will show next, we may find it in the work of the Austrian philosopher Ludwig Wittgenstein (as presented by Long [59]).

In order to further analyze the validity of the praxeological approach we need to respond to several objections against this view. The first one is what Mises [65, pp. $75-89]$ defined as "polylogism", the view that there is no such a thing as a universal logic. For praxeology, the problem with this view can be easily seen: if there is no universal logic, then there is no way to derive any empirical application (including economic theory) from the action axiom, which is based on the idea of identifying every human action as rational action. Here, the Austrian author is in the tradition of Frege $^{44}$ [59, pp. 346-349], who in turn opposed the idea of "psychologism," the view that the laws of logic are nothing more than a generalization of how men think. This is an important distinction, since we can define two different views of polylogism [59, p. 347]: normative and descriptive.

Frege explained that "the laws of logic are normative for thought because they are descriptive of reality; but they are not descriptive of thought" [59, p. 347]. This implies a reflectionist view of logic, i.e. the idea that reality in itself is logical ${ }^{45}$ and therefore our thinking, in order to reflect reality, ought to follow the laws of logic. The corollary of this approach is that logical thought is optional for man, meaning that although the proper way to think, if one wants to conform to reality, is by guiding thought according to the laws of logic, man can also think illogically. Now, for normative polylogism, which holds that "every group has its own logic, but they're all correct; each group's logic is valid for that group" [59, p. 347], the Fregean view described before is a proper response, since although men can think illogically, it does not follow that there are multiple logics. 
But what about descriptive polylogism? This view maintains that "different principles of logic describe the thinking of different groups, but it does not follow that all these different logics are equally valid; one might well be right and all the others wrong" [59, p. 347]. The problem here is more difficult, since although it could be said that there is no such thing as multiple logics, there is no standard by which to judge which one is correct. This is so because the Fregean approach could be easily dismissed by pointing out that what the Fregean thinks that are the laws of logic, is only what his group regards as the laws of Logic, which can be different from what other group may think. This in turn implies that there is no way of knowing which Logic is the correct one, and therefore normative polylogism appears again. In other words, in order to refute normative polylogism, one may very well fall into descriptive polylogism, thus finally returning to normative polylogism.

Although Frege discards this possibility by not paying attention to descriptive polylogism (implying that the only problem is normative polylogism), Mises does in fact recognize that there is a difficulty with descriptive polylogism that should be solved. ${ }^{46}$ In order to do that he adopts an impositionist approach to logic, which holds that the Logic of reality is in fact an imposition made by the subject to reality due to the structure of the human mind. As we can see, this is a standard Kantian approach. Thus, by adopting this position, Mises is discarding any possibility of illogical thought, due to the nature and functioning of the reasoning mind itself. However, at the same time there is no way for Mises to discard the chance that other beings have other mental structures, and thus, impose different categories on reality. ${ }^{47}$ Therefore, this problem brings us back to normative and descriptive polylogism.

According to Long [59, p. 355], the solution to this problem is to be found in the work of Ludwig Wittgenstein. Why? Because based on his work we may reject the approach both of Mises and Frege to the problem of polylogism. Instead, he presents a case for what we may define as a unified view on the subject of thought and reality. Thus,

[...] impositionism is rejected because it pictures logic as a constraint imposed by us on the world, while reflectionism is rejected because it pictures logic as a constraint imposed by the world on us. To think of logic as constraining something is to imagine, or try to imagine, how things would be without the constraint. Since neither talk of an illogical world nor talk of illogical thought can be made sense of, the whole question cannot be meaningfully asked and so may be dismissed in good conscience: 'in order to be able to draw a limit to thought, we should have to find both sides of the limit thinkable. <... We cannot think what we cannot think; so what we cannot think we cannot say either' [103, p. 49], [59, p. 366].

The unified view emanates from the fact that

It is a sign of confusion to say either that the logicality of the world has its source in the structure of thought or that the logicality of thought has its source in the structure of the world as though the logicality of thought and the logicality of the world were two different facts that need to be hooked together, rather than being two sides of the same fact [...] [59, p. 366].

How do we make sense of the fact that praxeological concepts may not apply in practice all the time?

[...] although it is true that empirical considerations come into play in determining whether a praxeological concept is applicable in a particular case, such empirical considerations cannot confine themselves to the sorts of purely quantitative magnitudes and repeatable experiments with which the physical sciences (supposedly) deal, but must instead involve the intuitive, interpretive method that Mises and Hayek, borrowing from the hermeneutical tradition, call verstehen $^{48}[59$, p. 358]. 
Thus,

In solving Frege's problem, Wittgenstein has solved Mises' problem as well. There can be a priori economic laws, because the terms that occur in those laws will be applicable only to phenomena that in fact obey those laws. [...] Mises agrees with Wittgenstein that economic categories legitimately apply only to those items that play the corresponding role in people's actions. He too invokes the specific example of coins, which count as money only if they are actually used to facilitate indirect exchange. That use is constitutive of money [59, p. 355].

Therefore, as Long [59, p. 359], explains by using a Kantian formula: ${ }^{49}$ praxeology without thymology ${ }^{50}$ is empty; thymology without praxeology is blind.

History, as such, is to be studied according to the previous approach since the historian identifies common phenomena according to praxeological concepts and deals with unique events by the use of verstehen [98, p. 8]. Thus, it can deal with specific men, ideas, events, and other historical data by using ideal types. How does it create these?

The aspect from which history arranges and assorts the infinite multiplicity of events is their meaning. The only principle which it applies for the systemization of its objects - men, ideas, institutions, social entities, and artifacts - is meaning affinity. According to meaning affinity it arranges the elements into ideal types [65, p. 59].

As Wittgenstein explained, illogical thinking cannot count as thinking ${ }^{51}$; and very much in the same way, irrational action cannot count as action.

To borrow a phrase from Hayek, the mind does not so much make rules as consist of rules [38, p. 18]; and a mind that 'consists of rules' cannot intelligibly be interpreted either as making rules (as though it might have left them unmade), or as having rules imposed on it (as though it might have been free of them) [59, p. 367].

Thus, praxeological categories are not only an essential feature of the human mind, but also are a fundamental part of our understanding of human action in reality. The example of Mises on money is a case in point: without the category of medium of exchange, we would only see "round plates of metal." This example may be compared to that presented by John Wisdom when he discussed if we can correctly deduce emotions by perceiving the external behavior of individuals in the case of a person's face and then deducing he is angry in the same way "we know a kettle's boiling - from the steam we guess at bubbles and the rest, and from the bubbles and the rest it's a deduction that it's boiling" [104, p. 209]. Although we may be making an illegitimate extrapolation by deducing a specific inner state from an external reaction, what underlies both examples is that in order to understand both phenomena one needs the correct concepts. In other words, in order to deduce anger (an internal, psychological state) from a specific face under specific conditions (an external, physiological reaction) one needs to have the appropriate concept. In this respect, one also needs to have the concept of action in order to identify it in reality. Otherwise, one would never see actions, but only specific movements.

We are able to find in the work of Wittgenstein a solid foundation for praxeology and another justification for Mises's contentions, and thus we can leave behind the problematic analytic/synthetic distinction. ${ }^{52}$ Therefore, "Wittgenstein's arguments for the conclusion that whatever counts as thought must embody logical principles can likewise be deployed to show that whatever counts as action must embody economic principles" [59, p. 367]. 


\subsection{Praxeology and Logic}

Since Mises compares praxeological concepts with those of logic, in the sense that these are both $a$ priori, this may lead to some confusions of their different natures in cognition. Praxeology consists of basic concepts, based on the action axiom, which are identifications of fundamental features of human nature. From this axiom, we derive the rest of the praxeological theorems.

It has been contended that no proposition could be derived from a concept, but only from another proposition [99, p. 4]. However, the problem here is that the concept of action is not understood in praxeology as specific, articulated, proposition, but an identification of a fact of reality: man acts. In addition, this fact may be stated in different ways, and later aid us in order to derive further implications of the axiom. It is not the proposition that defines "action" which gives rise to the concept or the theory that enables us to identify action in reality. Rather, it is the concept of action which in turn allows us to articulate it in a certain proposition. E.g., in order to define the concept "action", one must already have the concept; and the same applies for identifying action in reality, otherwise one would not be able neither to define it propositionally nor identify it in reality (for different ways of stating the action axiom see above [65, p. 11]).

Scarano $[99$, p. 4] contends that if praxeology is formal, then every proposition with the same structure of the action axiom should be regarded as a praxeological truth for sharing the same structure. I.e. if the action axiom ("every action is purposeful behavior") has the logical form "All $\mathrm{S}$ is $\mathrm{P}$," then every other proposition with such form (e.g. "All swans are black") should be regarded as apodictically true. Further, Scarano explains that for Kantians every synthetic a priori proposition is not true due to its form, but because of its content:

Secondly, if praxeology is formal, then any sentence with the same form would be true. The statement 'every conscious action presupposes ends', has the logical form 'if $\mathrm{P}$ then Q' and, therefore the following should be praxeological truths, "All men are happy', 'All whales have lungs'. None of these statements are considered as praxeological truths... Praxeological truths, or synthetic a priori truths as a Kantian would say, are not true for their form, but for their content! $[99, \text { p. } 4]^{53}$

However, Mises explains that the fact that man acts, i.e. he chooses means in order to attain certain ends, is true of any situation where such an event takes place, regardless of the means or ends chosen.

Praxeology is indifferent to the ultimate goals of action. Its findings are valid for all kinds of action irrespective of the ends aimed at. It is a science of means, not of ends. It applies the term happiness in a purely formal sense. In the praxeological terminology the proposition: man's unique aim is to attain happiness, is tautological. It does not imply any statement about the state of affairs from which man expects happiness [65, p. 15].

To act is to choose means to attain ends. As such, the form which Mises has in mind here is not the logical form of a proposition, but the specific sequence of events that are conceptualized under "action," choosing certain means in order to attain certain ends. The action axiom is not a logical proposition without content, but a specific concept, which abstracts from the given means and ends that any individual may choose, and only consider the structure of the event as such. Thus, the content of the axiom is its identification of a specific sequence of events that identify any situation where such sequence or phenomena take place, regardless of the specifics involved in the situation. ${ }^{54}$

Let us give an example from the field of mathematics in order to better illustrate the idea. A function is a set of ordered pairs where for each value of the independent variable corresponds a unique value of the dependent variable, but not necessarily vice versa. For instance, if we have the function $\mathrm{y}=$ 
$a_{0}+a_{1} x+a_{2} x^{2}$, where $a_{2}<0$, there may be the same value of $y$ for different values of $x$, but not the other way. As such, this function has the logical form of the modus ponens:

If $\mathrm{P}$, then $\mathrm{Q}$

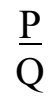

For any value of $\mathrm{x}$ there is a certain value of $\mathrm{y}$

$\underline{\mathrm{x}}$

Let us assume that for this parabolic function, the value of $\mathrm{y}=7$ may correspond both to $\mathrm{x}=2$ and $\mathrm{x}=$ 4. As such, if we then conclude from the fact that $y=7$ that $x=2$ we are committing the fallacy of affirming the consequent, since it may also be that $\mathrm{x}=4$. This is so because the logical reasoning implicit in the function is (modus ponens):

$$
\begin{gathered}
\text { If } x=2 \text { then } y=7 \\
x=2
\end{gathered}
$$

But if we say:

$$
\begin{gathered}
\text { If } x=2 \text { then } y=7 \\
y=7
\end{gathered}
$$

This is false, since the conclusion may also be $\mathrm{x}=4$.

The point of this example is to show that the underlying logic behind this mathematical reasoning is the modus ponens, but there are many possible applications of the same logical structure to propositions of different nature. Because praxeology studies the logic of action, this does not imply that logic is to be understood here as symbolic logic. From the fact that two reasoning have the same structure one cannot conclude that they have the same nature.

This example implies that although one may very well identify the logical structure of a certain reasoning, this does not imply that the reasoning itself is of a logical nature (in this case, its nature is mathematical). With the concept of human action something similar happens: we identify the underlying logic of the axiomatic proposition of action as purposeful behavior. Thus, Scarano's critique that praxeology is not sensible since it is not formalized and refers only to concepts such as those of logic is wrong; although the action axiom has logical implications, it is not by itself of a logical nature. In other words, although praxeology studies the structure of action, as logic studies the structure of reasoning and propositions, we must not conclude that praxeology is of the same nature as logic; only that both deal with the a priori.

Praxeology has a conceptual nature, and if we are to identify the logical structure of the action axiom, then it is not "All S is P" but "S if and only if $\mathrm{P}$ " $\left(\right.$ biconditional ${ }^{55}$ ). This is so because there is action if and only if there is purposeful behavior, i.e. only the choice of certain means to attain certain ends can be regarded as action. Thus, Wittgenstein's approach as presented supra applies in this regard. How so? Because the concepts of praxeology can only be applied to those situations where they identify reality, as such the concept of action applies if and only if someone acts. Therefore, the identity of the premises in the reasoning is the content of praxeology, but applicable to any phenomena which 
has the form of action, any action. It is not the same to say that "if there is behavior, then there is action", as to say, "If there is purposeful behavior, then there is action," despite of the fact that both propositions are of the form "If $\mathrm{P}$, then Q."

\subsection{Intuition and Introspection}

Another critique of praxeology is that it not only depends on intuition ${ }^{56}$ but also on introspection, and as such, it may be discarded as a form of subjectivism. However, this is not the case, since the Austrian approach does not rely on introspection in general, but only on introspection as a means of identifying the truth of the action axiom. How so? Since introspection is by itself an action, any introspective inquiry uses and thereby confirms the validity of the action axiom; regardless of the content of one's introspection (thus it is valid for inter-subjectivity). As for the rejection of "concepts of consciousness" (on which introspection depends), Binswanger [8, p. 54] explains:

The denial that we are self-aware is self-refuting: the denial maintains, in one form or another, that concepts of consciousness are invalid, that they do not represent an awareness of anything real. Since this claim presupposes knowledge of the distinction between contents of consciousness and external facts, it is just another form of denying the axiom of consciousness and commits the same stolen concept fallacy: the concept 'invalid' presupposes, implicitly or explicitly, the concept 'consciousness.' 'Invalid' refers to the status of an idea, a status that is differentiated from that of a valid awareness of fact. But making that distinction presupposes that we have recognized what it is to be aware of facts, which implies an act of self-awareness. The denial of introspective self-awareness presupposes what is being denied.

We are here attacking the idea that introspection is invalid as a source of knowledge, because if so, so is the case that praxeology is invalid as a methodology. Binswanger's approach is useful to explain why concepts of consciousness (which are the ones we reach by introspection, and give it validity) are reliable.

Further, it can be said that ${ }^{57}$ if we accept that there can be such a thing as a "reflex" or behavior that is not purposeful, we cannot be sure that we are identifying action (as purposeful behavior) in any specific situation. However, this would be nothing more than a reductio ad absurdum, since it is a fact of daily life of any individual that his usual approach towards interacting with others is to assume that these follow the concept of action as presented here, i.e. they choose certain means to attain their ends. ${ }^{58}$

The idea that men are motivated in general by "reflexes" or "unconscious movements" cannot be seriously contended nor applied as a usual policy. This is so because if "reflex" would be the standard of human behavior, then with what are we to contrast it in order to arrive to the concept of action? How could we make sense of any process of thought if we must assume that we are motivated just by "reflexes" and not by conscious awareness? Thus, there would be no way to explain not only the daily events in which human beings are involved, but also we would have to accept that civilization as we know it is the result of mere chance. Thus, an implication of the action axiom is that in every interaction with other individuals one has the expectation that these others will behave rationally (but, of course, not necessarily in a sensible way $)^{59}$; otherwise no theory could be constructed so as to explain human behavior in society ${ }^{60}$ (with its great complexity). An individual who acts has expectations that those with whom he exchanges will act rationally. This is the regularity that permits us to construct economic theory (or any theory of social cooperation in general).

The standard for any theory of human behavior as such should be rational action, because if we would take, for instance, sleepwalking as a standard then there is no reason to distinguish between 
conscious and unconscious behavior in the first place. To state that an industrial civilization may be the outcome of mere "reflexes" or unconscious reactions is nothing more than a reductio ad absurdum.

Moreover, rejecting the action axiom would imply that economic events (as a category of events in general) do not need to follow a means-ends structure not only in order to be understood, but also to exist at all. As Hayek [38] explained, many fundamental human institutions may not be and are not the result of human design, but human action. ${ }^{61}$ Following Mises's approach we can say that they are nevertheless the outcome of human reason in pursuing individual ends. They are an emergent ${ }^{62}$ outcome.

The fact that reason is fallible ${ }^{63}$ does not imply that it will necessarily be wrong. As such, whenever a certain behavior is interpreted as action while it was actually a reflex, we must conclude that there was an error of judgment, but not infer from this error that there is no such a thing as action, nor that a human being is unable, in principle, to identify it.

\section{Conclusion}

As we tried to show throughout this paper, the work of Ludwig von Mises in developing the field of Praxeology is highly useful in order to shed light on the concept of intentional action. Moreover, aided by the developments of other authors, such as Friedrich Hayek and Ludwig Wittgenstein (as presented by Long [59]), a solid foundation for praxeology is provided and thus a deeper understanding of the concept of action is achieved.

Intentional action is, under this approach, rational action, and therefore purposeful behavior. Although there are problems in the exposition and formulation of praxeology as presented by Mises ${ }^{64}$, it is nevertheless useful not only in identifying the nature of the category of action, but also its implications, thus expanding our knowledge on the concept of intentional action as such. Despite the fact that there have been enormous advances in the study of action in general and in the field of economics in particular, ${ }^{65}$ Mises's approach is able to give as a unique basis on the subject.

\section{References}

1. Anderson, W. Mathematics and Economic Analysis, Available at https://mises.org/library/mathematics-and-economic-analysis 2002

2. Barnett, W. II. The Modern Theory of Consumer Behavior: Ordinal or Cardinal? The Quarterly Journal of Austrian Economics, 6 (1), 2003, pp. 41-65.

3. Barnett, W. II. Dimensions and Economics: Some Problems, Quarterly Journal of Austrian Economics, Spring. Vol. 7, No. 1, 2004, pp. 95-104.

4. Barnett, W.II, \& W. E. Block. Rothbard on V shaped average and total cost curves, Quarterly Journal of Austrian Economics, Vol. 9, No. 3, Fall, 2006, pp. 61-66.

5. Barnett, W. II, \& W. E. Block. On Hayekian Triangles, Procesos De Mercado: Revista Europea De Economia Politica, Vol. III, No. 2, Fall, 2006, pp. 39-141.

6. Barnett, W., \& W. E. Block. Mises never used demand curves; was he wrong? Ignorant? No: The Antimathematicality of Demand Curves, Dialogue, Vol. 1, March 2010, pp. 23-31.

7. Batemarco, R. Positive Economics and Praxeology: The Clash of Prediction and Explanation, Atlantic Economic Journal, July, 13(2), 1985, pp. 31-27.

8. Binswanger, H. How We Know. New York: TOF Publications, 2014.

9. Block, W. E. A Comment on 'The Extraordinary Claim of Praxeology,' by Professor Gutierrez, Theory and Decision, Vol. 3, No. 4, June, 1973, pp. 377-387.

10. Block, W. E. On Robert Nozick's 'On Austrian Methodology,' Inquiry, Vol. 23, No. 4, Fall, 1980, pp.397-444. Spanish translation, Libertas, Vol. 14, No. 26, May, 1997, pp. 71-131. 
11. Block, W. E. Austrian Theorizing, Recalling the Foundations: Reply to Caplan, Quarterly Journal of Austrian Economics, Vol. 2, No. 4, 1999, pp. 21-39.

12. Block, W. E. Realism: Austrian vs. Neoclassical Economics, Reply to Caplan, Quarterly Journal of Austrian Economics, Vol. 6, No. 3, Fall, 2003, pp. 63-76.

13. Block, W. E. Reply to Caplan on Austrian Economic Methodology, Corporate Ownership \& Control, Vol. 4, No. 2, November, 2007, pp. 312-317.

14. Block, W. E. Rejoinder to Hoppe on indifference, Quarterly Journal of Austrian Economics, Vol. 12, No. 1, 2009, pp. 52-59.

15. Block, W. E. Rejoinder to Machaj on Indifference, New Perspectives on Political Economy, Vol. 5, No. 1, 2009, pp. 65-71.

16. Block, W E., \&W. Barnett II. Rejoinder to Hoppe on indifference, once again, Reason Papers, Vol. 32, 2010, pp. 141-154.

17. Boulding, K. E. After Samuelson, Who Needs Adam Smith? History of Political Economy, Vol. 3, No. 2, 1971, pp. 225-237.

18. Brätland, J. Human Action and Socially Optimal Conservation: A Misesian Inquiry into the Hotelling Principle, The Quarterly Journal of Austrian Economics 3, 1, 2000, pp. 3-26.

19. Bylund, P. The 'Mystery' of the Endowment Effect. Available at http://mises.org/daily/5839/TheMystery-of-the-Endowment-Effect, December 28, 2011.

20. Callahan, G. Logical Economics vs. Mathematical Economics. Available at

https://mises.org/library/logical-economics-vs-mathematical-economics, February 17, 2001.

21. Callahan, G. Choice and Preference. Available at

https://mises.org/library/choice-and-preference, February 10, 2003.

22. Caplan, B. Why I am not an Austrian Economist, Available at

http://www.gmu.edu/depts/economics/bcaplan/whyaust.htm, Undated.

23. Caplan, B. The Austrian Search for Realistic Foundations,Southern Economic Journal, April, Vol. 65, No. 4, 1999, pp. 823-838.

24. Caplan, B. Probability, Common Sense, and Realism: A Reply to Huelsmann and Block, Quarterly Journal of Austrian Economics; Vol. 2, No. 4, summer, 2001, pp. 69-86.

25. Caplan, B. Probability and the Synthetic A Priori: A Reply to Block, Quarterly Journal of Austrian Economics; Vol. 6, No. 3, Fall, 2003, pp. 77-83.

26. Caplan, B. The Trojan Horse Example, Available at

http://econlog.econlib.org/archives/2008/06/the trojan hors.html, June 16, 2008.

27. Champion, R. The Rise of Mathematical Economics. Available at

http://www.the-rathouse.com/2008/Ingrao-Israel.html 2008

28. Coase, R. H. The Problem of Social Cost, Journal of Law and Economics, 3, 1960, pp. 1-44.

29. Dolan, E. Austrian Economics as Extraordinary Science, In E. Dolan (ed.), The Foundations of Modern Austrian Economics, Kansas City: SheedandWard, Inc., 1976, pp. 3-18.

30. Fox, G. The Pricing of Environmental Goods: A Praxeological Critique of Contingent Valuation, Cultural Dynamics, Vol. V, No. 3, 1992, pp. 245-259

31. Gordon, S. History and Philosophy of Social Science. London: Routledge, 1993.

32. Gossen, H.H. Entwickelung der Gesetze des menschlichen Verkehrs, und der darausfließenden Regelnfürmenschliches Handeln. Braunschweig: Friedrich Vieweg und Sohn, 1854. English translation R. C. Blitz, The Laws of Human Relations and the Rules of Human Action Derived Therefrom. Cambridge, MA: MIT Press, 1983.

33. Garrison, R. W. Hayekian Triangles and Beyond, in Jack Birner and Rudy van Zijp(eds.), Hayek, Coordination and Evolution: His Legacy in Philosophy, Politics, Economics, and the History ofIdeas. London: Routledge, 1994, pp. 109-125. 
34. Garrison, R. W. Time and Money: The Macroeconomics of Capital Structure, London: Routledge, 2001.

35. Hayek, Friedrich A. Prices and Production, London: Routledge, 1931.

36. Garrison, R. W. The Use of Knowledge in Society, The American Economic Review, Vol. 35, No. 4. (Sep., 1945), pp. 519-530.

37. Garrison, R. W. Competition as a Discovery Procedure, Institut für Weltwirtschaft, Kiel University, No 56 Kieler Vorträge series, 1968. Trans. Marcellus S. Snow, Der Wettbewerbals Entdeckungsverfahren, The Quarterly Journal of Austrian Economics, Vol. 5, No 3 (Summer), 2002, pp. 9-23.

38. Garrison, R. W. Law, Legislation, and Liberty: A New Statement of the Liberal Principles of Justice and Political Economy, Vol. I, Rules and Order, Chicago: University of Chicago Press, 1973.

39. Garrison, R. W. The Pretense of Knowledge. Friedrich A. Hayek's Nobel Prize Lecture, Nobel Prize in Economics, Stockholm, Sweden, 1974. In A Free Market Monetary System and The Pretense of Knowledge, Auburn: Ludwig Von Mises Institute, 2008.

40. Hazlitt, H. The Failure of the "New Economics", New Rochelle, NY: Arlington House, 1959.

41. Herbener, J. M. Calculation and the Question of Mathematics, Review of Austrian Economics, 9(1), 1996, pp. 151-162.

42. Hoppe, H. H. In Defense of Extreme Rationalism: Thoughts on Donald McClosky's The Rhetoric of Economics, Review of Austrian Economics, 3, 1989, pp. 179-214.

43. Hoppe, H. H. Austrian Rationalism in the Age of the Decline of Positivism, Journal des Economistes et des Etudes Humaines, Vol.2, No. 2, 1991; reprinted as Hoppe, Hans-Hermann. Austrian Rationalism in the Age of the Decline of Positivism, In R. M. Ebeling (ed.), Austrian Economics: Perspectives on the Past and Prospects for the Future, Vol. 17, Hillsdale, MI: Hillsdale College Press, 1994, pp. 59-96.

44. Hoppe, H. H. On Praxeology and the Praxeological Foundation of Epistemology and Ethics, Herbener, J., ed., The Meaning of Ludwig von Mises, Boston: Dordrecht, 1992.

45. Hoppe, H. H. Economic Science and the Austrian Method, Auburn, AL: The Ludwig von Mises Institute, 1995.

46. Hoppe, H. H. A Note on Preference and Indifference in Economic Analysis, The Quarterly Journal of Austrian Economics, Vol. 8, No. 4, Winter, 2005, pp. 87-91.

47. Hoppe, H. H. Austrian Rationalism in the Age of the Decline of Positivism. In The Economics and Ethics of Private Property: Studies in Political Economy and Philosophy, Auburn AL: The Mises Institute, 2006, $2^{\text {nd }}$ ed.,pp. 347-379.

48. Hoppe, H. H. Further Notes on Preference and Indifference: Rejoinder to Block, The Quarterly Journal of Austrian Economics, 12, No. 1, 2009, pp. 60-64.

49. Hülsmann, J. G. Economic Science and Neoclassicism, Quarterly Journal of Austrian Economics, Vol. 2, $\mathrm{Nr}$ 4, 1999, pp. 1-20.

50. Hutt, W. H. The Keynesian Episode: A Reassessment, Indianapolis, IN: Liberty Press, 1979.

51. Ingrao, B. \& G. Israel. The Invisible Hand: Economic Equilibrium in the History of Science, Transl. by I. McGilvray, Cambridge and London: MIT Press, 1987 (1990).

52. Ischboldin, B. A critique of econometrics, Review of Social Economy, Vol. 18, No 2, September, 1960 .

53. Jablecki, J. How Many Traders Can You Fit into a Model? Available at https://mises.org/library/how-many-traders-can-you-fit-model, August 23, 2007

54. Kant, I. The Critique of Pure Reason. Project Gutenberg, Transl. by J. M. D. Meiklejohn, Available at http://www.gutenberg.org/files/4280/4280-h/4280-h.htm 1787 (2013).

55. Kirzner, I. Market Theory and the Price System. New York: D. Van Nostrand Co., 1963. 
56. Kirzner, I. The 'Austrian' Perspective on the Crisis, In Austrian Economics, Vol. 1, Edward Elgar, 1990, pp. 191-202.

57. Kotarbinski, T. Praxiology - An Introduction to the Sciences of Efficient Action, Trans. by O. Wojtasiewicz,Pergamon Press, 1965.

58. Leoni, B. \& E. Frola. On mathematical thinking in economics, The Journal of Libertarian Studies, Vol. 1, No. 2, 1977, pp. 101-110.

59. Long, R. T. Anti-Psychologism in Economics: Wittgenstein and Mises, The Review of Austrian Economics, 17:4, Kluwer Academic Publishers, 2004,pp. 345-369.

60. Machaj, M. A Praxeological Case for Homogeneity and Indifference, New Perspectives on Political Economy, Vol. 3, No. 2, 2007, pp. 231-238.

61. Menger, K. Austrian Marginalism and Mathematical Economics, In Carl Menger and the Austrian School of Economics, J.R. Hicks \& W. Weber(eds.), Oxford: Clarendon Press, 1973.

62. Mises, L. von. Socialism: An Economic and Sociological Analysis, New Haven: Yale University Press, 1922 (1962).

63. Mises, L. von. Epistemological Problems of Economics, Auburn: Ludwig Von Mises Institute, 1933 (2003).

64. Mises, L. von. The Equations of Mathematical Economics and the Problem of Economic Calculation in a Socialist State, The Quarterly Journal of Austrian Economics, Vol. 3, $\mathrm{N}^{\circ} 1$ (Spring), 1938 (2000), pp. 27-32.

65. Mises, L. von. Human Action - A Treatise on Economics, The Scholar's Edition, Auburn: Ludwig Von Mises Institute, 1949 (1998).

66. Mises, L. von. Theory and History - An Interpretation of Social and Economic Evolution, Auburn: Ludwig Von Mises Institute, 1957 (2007).

67. Mises, L. von. The Ultimate Foundation of Economic Science - An Essay on Method, New York: Van Nostrand, 1962.

68. Mises, L. von. Comments about the mathematical treatment of economic problems, The Journal of Libertarian Studies, Vol. 1, No. 2, 1977, pp. 97-100.

69. Menger, C. Principles of Economics, Auburn: The Ludwig Von Mises Institute, 1871 (2007).

70. Mirowski, P. Against Mechanism: Protecting Economics from Science, Rowman \& Littlefield, 1988.

71. Moorhouse, J C. A Critical Review of Mises on Mathematical Economics, History of Economics Review, Vol. 20, Issue 1, 1993.

72. Murphy, R. P. Austrian Realists, Available at

https://mises.org/library/austrian-realists, July 17, 2008.

73. Murphy, R. P., R. Wutscher, W. E. Block. Mathematics in Economics: An Austrian Methodological Critique, Philosophical Investigations, Vol. 33, No 1, 2010, pp. 44-66.

74. Nozick, R. On Austrian Methodology, Synthese, Vol. 36, 1977, pp. 353-392; Reprinted in Socratic puzzles, Harvard University Press, 1997.

75. O'Neill, B. Choice and Indifference: A Critique of the Strict Preference Approach, Quarterly Journal of Austrian Economics, Vol. 13, No.1, 2010, pp. 71-98.

76. Polleit, T. Mises's Apriorism Against Relativism in Economics, Available at https://mises.org/library/misess-apriorism-against-relativism-economics, April 25, 2008.

77. Polleit, T. True Knowledge from A Priori Theory, Available at http://mises.org/daily/5349/True-Knowledge-from-A-Priori-Theory, June 8, 2011.

78. Popper, K. The Poverty of Historicism, London: Routledge, 1957 (2002).

79. Quine, W. V. Two Dogmas of Empiricism, The Philosophical Review, Vol. 60, No. 1. January, 1951, pp. 20-43. 
80. Reekie, W. D. The Austrian Response at a Micro Level, In Markets, Entrepreneurs, and Liberty, Wheatsheaf Books, 1984, pp. 27-55

81. Reekie, W. D. The Austrian Macro Retort, In.Markets, Entrepreneurs, and Liberty, Wheatsheaf Books, 1984, pp. 56-84.

82. Rizzo, M. J. Praxeology and Econometrics: A Critique of Positivist Economics, In L. M. Spadaro (ed.), New Directions in Austrian Economics, Kansas City: Sheed Andrews and McMeel, 1978.

83. Rizzo, M. J. The Problem of Rationality: Austrian Economics Between Classical Behaviorism and Behavioral Economics, In P. J. Boettke, Ch. J. Coyne, The Oxford Handbook of Austrian Economics, New York: Oxford University Press, 2015, pp. 364-392.

84. Ropke, W. The Place of Economics Among the Sciences, In M. Sennholz (ed.), On Freedom and Free Enterprise, Princeton, NJ: D. Van Nostrand Co., 1956, pp. 111-127.

85. Rothbard, M. N. Praxeology: Reply to Mr. Schuller, American Economic Review, December, Vol. 41, No. 5, 1951,pp. 943-946.

86. Rothbard, M. N. The Mantle of Science, In The Logic of Action One, Cheltenham, UK: Edward Elgar, 1997, pp. 3-23. Originally published in H. Schoek \& J. W Wiggins (eds.), Scientism and Values, 1960.

87. Rothbard, M. N. Man, Economy and State. Scholar's Edition, Second Edition. Auburn: Ludwig Von Mises Institute, 1962 (2009).

88. Rothbard, M. N. Lange, Mises and Praxeology: The Retreat from Marxism, Toward Liberty. Vol. II, Menlo Park, CA: Institute for Humane Studies, 1971, pp. 307-321. Reprinted in The Logic of Action One: Method, Money, and the Austrian School, Glos, UK: Edward Elgar Publishing Ltd., 1997, pp. 384-396.

89. Rothbard, M. N. Praxeology and the Method of Economics, Phenomenology and the Social Sciences, M. Natanson(ed.), Evanston, IL: Northwestern University Press, vol. 2, 1973, pp. 311-342; and Austrian Economics: A Reader Vol. 18, Richard M. Ebeling (ed.), Hillsdale, MI.: Hillsdale College Press, 1991, pp. 55-91.

90. Rothbard, M. N. Toward a Reconstruction of Utility and Welfare Economics, San Francisco: Center for Libertarian Studies, 1977, Occasional Paper \#3.

91. Rothbard, M. N. Chaos Theory: Destroying Mathematical Economics from Within? The Free Market, Vol. VI, No. 3, 1988.

92. Rothbard, M. N. Praxeology as the Method of the Social Sciences, In M. N. Rothbard (ed.), The Logic of Action One, Edward Elgar Publishing Limited, 1997, pp.28-57.

93. Rothbard, M. N. Praxeology: The Methodology of Austrian Economics, In M. N. Rothbard (ed.), The Logic of Action One, Edward Elgar Publishing Limited, 1997, pp.58-77.

94. Rothbard, M. N. Praxeology, Value Judgments, and Public Policy, In M. N. Rothbard (ed.), The Logic of Action One, Edward Elgar Publishing Limited, 1997, pp.78-99.

95. Rothbard, M. N. In Defense of 'Extreme Apriorism,' Southern Economic Journal, January 1957, pp. 314-320; reprinted in M. N. Rothbard (ed.), The Logic of Action One, Edward Elgar Publishing Limited, 1997, pp.100-108.

96. Rothbard, M. N. Daniel Bernoulli and the Founding of Mathematical Economics, Available at https://mises.org/library/daniel-bernoulli-and-founding-mathematical-economics, February 10, 2011.

97. Selgin, G. A. Praxeology and Understanding: An Analysis of the Controversy in Austrian Economics, Review of Austrian Economics, (2), 1988, pp. 19-58; and Praxeology and Understanding, Auburn, AL: Ludwig von Mises Institute, 1990.

98. Scarano, E. R. El Apriorismo de Ludwig Von Mises, Revista Libertas, $\mathrm{N}^{\circ}$ 40. Available at http://www.eseade.edu.ar/files/Libertas/1_2_Scarano.pdf, Mayo, 2004.

99. Scarano, E. R. Las Dificultades de la Metodología Miseana, Congreso Internacional "La Escuela Austríaca en el Siglo XXI," Rosario, Argentina. Available at 
http://austrianeconomicsconference.org/ponencias/2006/Scarano01.pdf 2006

100. Shostak, F. What is Wrong with econometrics? Available at

https://mises.org/library/what-wrong-econometrics, April 17, 2002.

101. Smith, V. Reflections on Human Action After 50 Years, Cato Journal, Vol. 19, No. 2. Fall. Cato Institute, 1999.

102. Spadaro, L. M. Averages and Aggregates in Economics, In M. Sennholz (ed.), On Freedom and Free Enterprise, Princeton, NJ: D. Van Nostrand Co., 1956, pp. 140-60.

103. Wittgenstein, L. Tractatus Logico-Philosophicus, Trans. by D. F. Pears \& B. F. McGuinness, London: Routledge, 1961.

104. Wisdom, J. Proceedings of the Aristotelian Society, Vol. XX, In Other Minds, Berkeley and Los Angeles: University of California Press, 1968.

105. Wutscher, R. Foundations in economic methodology: The use of mathematics by mainstream economics and its methodology by Austrian economics, Available at http://www.mises.org/journals/scholar/Wutscher.pdfUnpublished

106. Zanotti, G. Fundamentos Filosóficos y Epistemológicos de la Praxeología, Tesis Doctoral, Instituto Acton, 1990 (2004).

\section{Notes}

1. The authors wish to thank Rafael Beltramino for helpful comments on an earlier draft of this paper.

2. For another approach on praxeology, see [57].

3. Lemberg, Austria, 09/29/1881 - New York, United States, 10/10/1973.

4. The present authors would include in this regard Murray N. Rothbard, even though he is lesser known that those two.

5. A "defense of free enterprise" is normative. The action axiom is an aspect of positive economics. Never the twain shall meet? See below.

6. Others include [9], [10], [11], [7], [30], [42], [43], [44], [45], [49], [76], [77], [82], [85], [86], [87], [88], [89], [92], [93], [94], [95], [97]. Further, virtually all of these are in effect standing on the intellectual shoulders of Mises.

7. "Action is a category that the natural sciences do not take into account. [...] There are constant relations between entities that enable the scientist to establish the process called measurement. But there is nothing that would suggest aiming at ends sought; there is no ascertainable purpose" [67, pp. 6-7].

8. Although it could be said that there is no such thing as ceteris paribus in any science, it is certainly possible to distinguish among different conditions for the application of the concept: 1 . When the exact formal conditions which allow the application of a proposition hold; 2 . When the variables not included in the theory are irrelevant or constant; 3 . When such variables are neither relevant nor constant but have turned out to be so in a laboratory; and 4. The variables not included in the theory are neither constant nor irrelevant nor established in a laboratory, but we accept the current hypothesis arguendo until we can make a new one which includes them [31]. We can infer that Mises refers here to the fact that formal sciences apply for 1 , the natural sciences for 2 and 3, but economics pertains to 4 .

9. A similar situation pertains with regard to equilibrium, or the evenly rotating economy. States Mises [62, p. 163] in this regard: "To assume stationary economic conditions is a theoretical expedient and not an attempt to describe reality. We cannot dispense with this line of thought if we wish to understand the laws of economic change. In order to study movement we must first imagine a condition where it does not exist. The stationary condition is that point of equilibrium to which we conceive all forms of economic activity to be tending and which would actually be attained if new factors did not, in the meantime, create a new point of equilibrium. In the imaginary state of equilibrium all the units of the factors of production are employed in the most economic way, and there is no reason to contemplate any changes in their number or their disposition. Even if it is impossible to imagine a living - that is to say a changing - socialist economic order, because economic activity without economic calculation seems inconceivable, it is quite easy to postulate a socialist economic order under stationary conditions. We need only avoid asking how this stationary condition is achieved. If we do this there is no difficulty in examining the statics of a socialist community. All socialist theories and Utopias have always had only the stationary condition in mind." (emphasis in the original).

10. There are no constants in economics as there are in the natural sciences, such as gravity, or the periodic table of the elements in chemistry.

11. See Mises on Case Probability and Class Probability [65, pp. $107-113]$.

12. This insight by Mises was many decades later adopted by philosopher of science Karl R. Popper [78]. 
13. Although the conception of axioms as self-evident has been abandoned at the beginning of the $20^{\text {th }}$ century, this in turn works in favor of Mises, since it does not oblige him to justify the action axiom as the only and most fundamental basis for any knowledge, or knowledge as such. Despite of the fact that Mises indeed wants to prove that it is an axiom.

14. "Axiomatic Nature" is to be regarded in the sense of the self-evidence. However, as we have previously said in fn. 13, if axioms need not be self-evident, but chosen for a system, then there is no such a thing as axiomatic nature. Even so, we use the phrase as to follow Mises's idea on this regard; which does not alter the reasoning. The action axiom is apodictic, since any attempt to deny it is also a human action.

15. "[...] to distinguish precisely, within the broader field of general praxeology, a narrower orbit of specifically economic problems [...] All that can be contended is this: Economics is mainly concerned with the analysis of the determination of money prices of goods and services exchanged on the market. In order to accomplish this task it must start from a comprehensive theory of human action [...] it must not restrict its investigations to those modes of action which in mundane speech are called 'economic' actions, but must deal also with actions which are in a loose manner of speech called 'noneconomic'" [65, pp. 233-235].

16. Although not everything that seems evident is irrefutable nor everything that is irrefutable $i s$ evident, we will address possible objections throughout this paper in order to defend this view with respect to the action axiom.

17. The causes of the ends aimed by every action is studied by the field of psychology.

18. Despite of the fact that if we are to adopt the analytic/synthetic distinction we may discard the empirical validity of the action axiom as a mere analytic truth (or a tautology), and thus analyze this approach from a strict positivist view, we will deal with this objection by pointing out its contradictions further in the text.

19. Since we are approaching this subject matter from the point of view of methodological dualism, a falsifiability criteria such as Popper's need not apply to define this approach as scientific or not.

20. See [64]. For a critique see [71]. Other Austrians, too, reject mathematical economics. Austrian economists who object to the hyper-mathematicalization of the dismal science include: [1], [2], [3[3], [4], [6], [18], [19], [20], [40, pp. 98-106], [41], [50, pp. 99-103], [53], [56], [58], [61], [64], [68], [72], [73], [80], [81], [82], [84], [86], [87], [91], [93], [96], [100], [102], [105]. There are even some economists not usually associated with the Austrian School who also oppose this hypermathematicalization of economics: [17], [27], [29], [51], [52], [70].

21. It is possible to formalize the theory with the help of symbolic logic, but functions are useful as well and we pursue that path at present. Why? Garrison [33], [34] inverted the triangle of Hayek [35] and Rothbard [87], placing time on the horizontal, not the vertical axis. Why did he do so? This was done in order to make the triangle, a pillar of Austrian business cycle theory, more amenable to mainstream economists, who are accustomed to that practice and might reject the triangle out of hand for this one characteristic. It is only in like manner that we employ mathematical format; for the same precise reason: to render Austrian economics more palatable to the profession, which is mainly neoclassical, and more than likely to reject praxeology for that reason alone (The popularity of Coase, [28] is an exception to this general rule.). As for the present authors, we join [5] in rejecting the triangle holus bolus, and, also, with the economists mentioned, supra, in the present footnote, who reject mathematical notation.

22. If he could do so, we would have achieved post scarcity. Then, there would be no need for human action, nor economics, which is its study.

23. Are we now treading in the direction of illegitimate cardinal utility? Austrianism is only compatible with ordinal utilty. Let us reassure the reader that we are not. That is why we say that the individual orders his ends in a ranking, and he values his means in proportion to how he values the ends he intends to achieve with them; i.e. in relation to them. But we do not say that the value of the means is equal to the value of the ends. We intend to say that, for example, the individual values E1 more than $\mathrm{E} 2(\mathrm{vE} 1>\mathrm{vE} 2)$; and the unit of means with which he intends to achieve E1 will be valued according to how he values E1 (vE1). Note that the values do not equalize; or that we can somehow measure them. In fn. 21 and 26 we say that formalization is done only for illustrative purposes.

24. Menger [69], by using the word "marginal" meant "additional."

25. Let us note that the praxeological deduction of diminishing marginal utility is based on the fact that the first unit of means is used for the attainment of the highest ranked end, the second unit for the second ranked end, etc. regardless of the psychological satisfaction (reported utility) that the individual gets at each time. On the other hand, Gossen's Law [32] (which is often used by neo-classical economists in order to illustrate this theory) is based on the idea that successive consumption of units of the same commodity will provide less utility each time. However, this depends on the commodity and the individual. For instance, the second unit may provide more satisfaction than the first one, and the third more than the second, etc. It is only eventually that we reach a point of diminishing returns. As such, it cannot be necessarily true, as are the categories of praxeology. In effect, this in turn implies that for praxeology marginal utility theory is not based on psychologism, and as we will see in section 5.i., this is relevant for the entire praxeological approach towards human action. 
26. Since there is no continuity in the field of human action (because man only regards discrete quantities as relevant for action), to derivate a function makes no economic sense. However, this formalization is intended to illustrate the postulates of praxeology, not to replace their conceptual truth, which is mainly shown in discursive reasoning.

27. Thus, economic goods are those which are scarce.

28. Let us be clear on this "value scale" business. It is not as if, on the one hand, we have the person, and on the other, his "value scale" that, perhaps, he is clutching in his hand, and consults, from time to time, before he acts. Rather, this value scale is implicit in his behavior. He chooses an apple instead of a banana, when offered both. On his value scale, the former ranks higher than the latter. We discover this, through his choice. However, he had no separate, perhaps printed, value scale, that he consulted. It is entirely possible, very likely even, that he was not thinking about fruit just before the moment he was offered this choice. It is highly plausible the even he did not know, beforehand, which he would partake in; that even he only discovered this ranking as he reached out his hand and grabbed up the apple.

29. "But acting man chooses, determines, and tries to reach an end. Of two things both of which he cannot have together he selects one and gives up the other. Action therefore always involves both taking and renunciation" [65, p. 12].

30. Thus, it would be impossible for anyone to demonstrate that he was indifferent between any two or more options. $\mathrm{He}$ could say he was indifferent, but how could he reveal (in the Rothbardian, [90]) sense, that he was? He could not.

31. Otherwise, why did he make that choice? Neoclassical indifference analysis is based on the idea that there is such a thing as indifference in human action (as presented in indifference curves and utility maximization analysis). Nozick [74, $\mathrm{p}$. 369] argues that marginal utility theory requires indifference in order to explain why the agent may choose any of the units he possesses to achieve an end; thus, he avers, the Austrian rejection of the concept of indifference is self-refuting. But if the agent were truly indifferent between the aforementioned apple and banana, why, ever, would he pick one and not the other. For the Austrian critique of the concept of "indifference" in economics, see [2], [10], [11], [12], [13], [14], [15], [16], [46], [48], [49], [60]. For a neoclassical rejection of this Austrian view, and thus a defense of the mainstream doctrine of "indifference" see [22], [23], [24], [25], [26], [74], [75]. See also on this [106, p. 22]: "Nozick has objected that from the fact that one person chooses $a$ does not imply that it does not want nor prefer $b$. It is true. But our contention that every action implies choosing between $a$ and $b$ does not mean deducing that the person does not prefer $b$, rather that since not every necessity could be satisfied at the same time, then the acting agent must create a value scale and set his priorities, according to which he will option. Perhaps, respect to this observation by Nozick we may say that every action implies to choose between $a$ and non $a$ " (translated by the first of the present authors from the original in Spanish, with permission of the original author).

32. Menger [69] classified economic goods in lower and higher order. Thus, lower order goods (or first order) are consumption goods, and those of higher order (or second, third, .., $n$ orders) are those which are used in the production process of lower order goods, classified as such according to how far they are from the consumption stage. Savings implies economic agents sacrificing present consumption in order to create higher order goods, which in turn can increase future consumption.

33. Which takes place before the advent of refrigeration.

34. Thus, the metaphysical status of the category of causality is outside the scope of praxeology. This is so because it is irrelevant for the acting agent: Whatever its metaphysical status, it must take it into account for the very nature of intentional action as such.

35. For a full analysis of praxeology see [65] and [106].

36. As presented in the previous section (4.c). "Choosing means is a technical problem, as it were, the term 'technique' being taken in its broadest sense. Choosing ultimate ends is a personal, subjective, individual affair. Choosing means is a matter of reason, choosing ultimate ends a matter of the soul and the will" [66, pp.14 - 15].

37. One of the characteristics of "Perfect Competition." See Kirzner [55].

38. See Rizzo [82, p. 50].

39. Some disciples of Mises, such as the American economist Murray Rothbard, use an Aristotelian foundation for the action axiom. "All human beings act by virtue of their existence and their nature as human beings. We could not conceive of human beings who do not act purposefully, who have no ends in view that they desire and attempt to attain. Things that did not act, that did not behave purposefully, would no longer be classified as human." (emphasis in the original) [87, p. 2]; this author also cites Aristotle's Ethica Nicomachea, ch. vii, as the basis for his contention on the nature of action. See also [93], [95].

40. "All that is needed for the deduction of all praxeological theorems is knowledge of the essence of human action. It is a knowledge that is our own because we are men; [...] no experience, however rich, could disclose them to a being who did not know a priori what human action is. The only way to a cognition of these theorems is logical analysis of our inherent knowledge of the category of action. We must bethink ourselves and reflect upon the structure of human action. Like logic and mathematics, praxeological knowledge is in us; it does not come from without" [65, p. 64]. 
41. This fact may answer the contention that the a priori nature of mathematics and logic is demonstrable, while praxeology is not [98, p. 11]. “...axiomatic concepts are only implicit in experience. To identify them explicitly, to conceptualize them, requires a sophisticated development" (emphasis in the original) [8, p. 168].

42. Mises also said on this regard that "No talk about irrationality [...] can invalidate the statement that man makes use of his reason for the realization of wishes and desires. From the unshakable foundation of the category of human action praxeology and economics proceed step by step by means of discursive reasoning. Precisely defining assumptions and conditions, they construct a system of concepts and draw all the inferences implied by logically unassailable ratiocination. With regard to the results thus obtained only two attitudes are possible; either one can unmask logical errors in the chain of the deductions which produced these results, or one must acknowledge their correctness and validity" [65, p. 67].

43. "Now we can begin to see why it is a mistake to assimilate what the praxeologist does to what a Cartesian rationalist does when he spins out the laws of physical motion a priori. The conclusions of praxeology are not in themselves empirical statements. They do not predict what people will do. For example, they do not predict how people will behave with regard to metal disks and piles of wood. What they do predict is how people will behave so long as they are buying and selling. If that gives praxeology empirical content, then geometry has empirical content in just the same way. Geometry cannot predict how many edges your next slice of pizza will have; but it can predict how many edges it will have so long as it is triangular" (emphasis in the original) [59, p. 356].

44. Perhaps by the influence of Edmund Husserl.

45. While we respect Frege, the present authors do not accept his view that reality is "logical." We maintain that it just is. See on this Wittgenstein, below.

46. We follow Long's presentation [59]; Mises does not present his case specifically in this way.

47. [...]"by granting that such categories apply to the world only because we impose them on it, it leaves open the possibility that creatures of another sort might impose different categories [...] the reflectionist position, echoing Frege's view that logical principles are laws of reality rather than laws of though [...] too seems vulnerable to polylogism. If the principles of psychology are normative for rather than constitutive of thought, then thought can depart from them; and once illogical thought is permitted, so is irrational action, and the fabric of praxeology is rent asunder" [59, p. 366]. Mises also points out that unconscious behavior may be difficult to distinguish from conscious behavior.

48. In Mises's analysis, Verstehen could be identified with Bergson's concept of Intuition [98, p. 6]. However, the approach here is not the same. The concept of intuition often responds to subjectivism and thus to relativism, turning it into an invalid source for objective knowledge. The idea is that experience is interpreted by a priori praxeological concepts, not that there is some kind of revelation that allows the individual to identify reality as it is without a specific means of cognition (in this case, the use of man's mind aided by praxeological concepts).

49. "Thoughts without content are void; intuitions without conceptions, blind" [54].

50. “"Thymology' is derived from the Greek $\theta v \mu o ́ s$, which Homer and other authors refer to as the seat of the emotions and as the mental faculty of the living body by means of which thinking, willing, and feeling are conducted.” [66, pp. 265 266].

51. "Wittgenstein's view is that we must go beyond the descriptive-normative dichotomy to the position that the laws of logic are constitutive of thought. Without logic there is no thought and without thought there is no objective substratum of communication." (emphasis ours) [83, p. 377].

52. See Quine [79]. Thus, we do not have to respond to the reasons for the rejection of synthetic a priori propositions as presented in Scarano [99, p. 5].

53. Translated by the first of the present authors from the original in Spanish, with permission of the original author.

54. This may be presented as the reason why Mises seems to avoid distinguishing between primitive and defined terms, as well as axioms and theorems in the strict sense. He also does not specifically state theorems nor constructs nor proves a definite system where praxeological truth belongs to both the axioms and the theorems (such is a part of the critique by Scarano, [98, p. 9]). The key here is that although the concept of action may be defined only ostensively, it is nevertheless axiomatic.

55. A $\mathrm{A}$.

56. We discussed this problem in section 5.1.

57. As we have said in section 5.1 .

58. The concept of reflex is only used to identify such behavior that cannot be said to be an action, i.e. purposeful behavior. But it is not nor cannot be used primarily as an approach to human behavior in general.

59. Nevertheless, this pertains to evaluations, not mere descriptions of action as such. That is, their actions will be purposive, and rational in the ex ante sense. But they are of course not always so ex post. That is people make mistakes, but do not intend to do so. 
60. It could be contended that there are certain events where the individual expects the other parties to behave irrationally, such as in war. But here also the action axiom is valid, since even when human beings act to destroy each other, they choose what they regard the best means in order to achieve that end. Rational here refers only to 'instrumental' rationality.

61. Examples include the spontaneous order creation of language and money. No one intended that they be created, but they came about as a result of human action.

62. Austrian economics, especially of the Hayek [36], [37], [38], [39] variant, explain that the economy is a complex system where institutions appear as an emergent property, not due to design but because of spontaneous orders. This in turn explains why central planning fails: it does not take into account that emergent properties of certain systems, such as social organization, cannot be emulated by a central authority. There is, fundamentally, a knowledge problem that the price system (in part) tends to solve under a free market.

63. This fact, (as we have seen in section III) is also recognized by praxeology, which in turn is the basis for the uncertainty of the future as well as for the existence of both profit and loss (section IV).

64. We presented several objections to this methodology and their possible answers throughout this work.

65. For an analysis of Human Action in the light of Experimental Economics, see [101]. 